\title{
Symmetric Volume-Reduction Plasty of the Enlarged Left Atrium: 15-years clinical experience
}

\author{
Sergey L Dzemeshkevich*, Vladimir V Raskin, Andrey S Dzemeshkevich, Yulia V Frolova, Sergey V Korolev, \\ Maria S Malikova, Alexey N Lugovoy \\ From World Society of Cardiothoracic Surgeons 25th Anniversary Congress, Edinburgh \\ Edinburgh, UK. 19-22 September 2015
}

\section{Background/Introduction}

Atriomegaly as a complication of mitral valve disease leads to atrial blood transport dysfunction, atrial fibrillation, respiratory insufficiency and heart failure.

\section{Aims/Objectives}

To analyze the results of treatment of all concomitant cardiac pathologies including atriomegaly during original surgical correction of mitral valve disease.

\section{Method}

From December 1998 to December 2013 we performed symmetric volume-reduction plasty of the left atrium (LA) in 104 patients with mitral valve disease using a technique we developed: we began the superior suture on the top of LA, above the line between the superior pulmonary veins; the right and left sutures were begun more laterally than the ostium of the inferior pulmonary veins, while on the left side we took into the suture the inner part of the left auriculum. All three sutures were tied up in the center of the posterior LA. Most of patients (87 cases) had a chronic form of atrial fibrillation and were in NYHA class IV. Mean age was 53,4+ 11 years. Procedures consisted of left atrium plasty (104 cases), mitral valve surgery (104 cases), tricuspid annuloplasty (47 cases), right atrium plasty (29 cases), aortic valve replacement (20 cases), left atrium thrombectomy ( 7 cases), coronary artery bypass grafting ( 5 cases), artificial chorde implantation (5 cases).

\section{Results}

There were 2 in-hospital deaths (1,9\%). The size of left atrium after surgery decreased from $8,3+2,1 \times 6,7+1,4 \mathrm{~cm}$

\footnotetext{
Department of Cardiac Surgery, Petrovsky National Research Centre of
} Surgery, Moscow, 119991, Russia (range 5 to $14,5 \mathrm{~cm}$ ) to $5,0+1,3 \times 4,7+1,1 \mathrm{~cm}$. The cardiothoracic ratio decreased from $0,62+0,04$ to $0,53+0,02$. The tracheal bifurcation angle decreased from $94,3+5,3^{\circ}$ to $76,0+6,3^{\circ}$. The follow-up data from 12 months to 15 years were available for 89 pts, and 54 pts $(60.7 \%)$ among them reported the sinus rhythm.

\section{Discussion/Conclusion}

Clinical, functional and anatomic results support the use of this original surgical technique of the symmetric atrial plasty for treatment of enlarged left atrium in patients undergoing mitral valve surgery. These data support the critical mass hypothesis of atrium fibrillation.

doi:10.1186/1749-8090-10-S1-A195

Cite this article as: Dzemeshkevich et al:: Symmetric Volume-Reduction

Plasty of the Enlarged Left Atrium: 15-years clinical experience. Journal of Cardiothoracic Surgery 2015 10(Suppl 1):A195.

Submit your next manuscript to BioMed Central

- Convenient online submission

- Thorough peer review

- No space constraints or color figure charges

- Immediate publication on acceptance

- Inclusion in PubMed, CAS, Scopus and Google Schola

Submit your manuscript at

C Biomed Central 